\title{
Hallazgos del uroanálisis y coprológico en niños indígenas Embera y Huitoto de Florencia, Caquetá- Colombia-, durante el primer periodo del 2012
}

\author{
Martha Castillo Bohórquez MSc ${ }^{1}$, Ana Isabel Mora Bautista MSc ${ }^{1}$, \\ Ana Lucia Oliveros Rozo Mag ${ }^{1}$, Leidy Milena Jiménez Tobo ${ }^{2}$, \\ Luz Myriam Parrales Solarte ${ }^{2}$, Nancy Carolina Suarez Católico². \\ ${ }^{1}$ Docentes investigadoras semillero ERITRON de la Universidad Colegio Mayor de Cundinamarca. \\ ${ }^{2}$ Estudiantes del programa de Bacteriología y Laboratorio Clínico de la Universidad \\ Colegio Mayor de Cundinamarca.
}

Correspondencia: mlcastillo@unicolmayor.edu.co

Recibido: 08/08/2012 Aceptado: 19/10/2012

\begin{abstract}
Resumen
Loshallazgosencontradosen elcoprológicoyuroanálisisen niñosindígenas HuitotosyEmberasquehabitanenlaciudaddeFlorencia, Caquetá,demostraron la presenciadeparasitismointestinalen un 78.9\%, mientras que bacterias nitritos positivos y leucocitosis en el parcial de orina en un porcentaje de $4.8 \%$. De acuerdo a los resultados, se sugiere implementar campañas de promoción de la salud y prevención de estas enfermedades con el fin de mejorar el estado de salud y las condiciones sanitarias de la población infantil de estos grupos étnicos.
\end{abstract}

Palabras clave: Huitotos, Emberas, Caquetá, parasitismo intestinal, infección urinaria.

\section{Urinalysis and stool analysis findings in Embera and Huitoto indigenous children of Florencia, Caquetá during the first period of 2012}

\begin{abstract}
In this study were found urinary tract infection and intestinal parasitism in Embera and Huitoto indigenous children of Florencia (Caqueta, Colombia). Urinalysis and stool analysis were also carried out in adults as contribution from the research to these communities. The laboratory results showed that $4.8 \%$ of the 21 children participating in the study had urinary tract infection and the $78.9 \%$ intestinal parasitism with more than one parasite by individual. Accordingly with these results, the research group suggests the implementation of health promotion and prevention campaigns in order to improve the health level of the ethnics group's child population. Key Words: Huitotos, Embera, Florencia, Intestinal parasitism, urinary tract infection.
\end{abstract}




\section{Introducción}

La ciudad de Florencia, Caquetá en Colombia alberga diferentes grupos indígenas tanto nativos como provenientes de otras regiones del país, producto del desplazamiento forzado. Ejemplo de lo anterior son las comunidades Huitoto y Embera quienes habitan en invasiones ubicadas en la periferia de la ciudad. Esta situación conlleva a que sean más susceptibles a padecer problemáticas en salud que afectan principalmente a la población infantil (1).

Las condiciones sanitarias poco óptimas, la calidad del agua de consumo, el lavado de manos inapropiado, el consumo de alimentos contaminados y el mal manejo de excretas favorecen la presencia del parasitismo intestinal. Otros factores como el uso de baños contaminados, malos hábitos de higiene, entre otros, pueden ocasionar infecciones urinarias identificadas en el parcial de orina por la presencia de microorganismos, leucocitos, hematíes y nitritos positivos en el caso de una infección bacteriana (2).

De esta forma, es indispensable valorar el estado de salud de los niños de las comunidades indígenas Huitoto y Embera, a partir de pruebas de laboratorio, identificando las patologías que afectan a la comunidad y de esta manera generar una intervención por parte de las entidades gubernamentales, que contribuya al mejoramiento de la calidad de vida de esta población.

\section{Materiales y métodos}

Sensibilización y consentimiento informado. Se hizo una sensibilización previa para la recolección de las muestras, que se dirigió a los cabildos Muido Yasikú, Embera Chami Hondura y Embera Chami País Amazonía; el primero perteneciente a la comunidad indígena Huitoto y los últimos a la comunidad indígena Embera, residentes en la ciudad de Florencia, Caquetá para dar a conocer la importancia del estudio y las condiciones que debían cumplir. Posteriormente, se entregó a los padres de cada individuo el consentimiento informado, para ser leído y firmado por quienes aceptaban participar libremente en el estudio, el total de participantes fue de 21 niños, Figura 1.

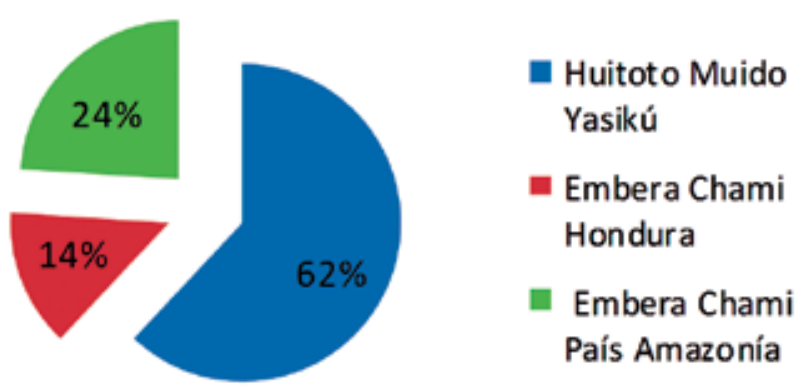

Figura 1. Porcentaje de participantes por comunidad de un total de 21 niños indígenas.

Procesamiento de muestras. Las muestras se procesaron en el Hospital Comunal de las Malvinas, la orina fue sometida a un análisis físico, químico y microscópico según la metodología estandarizada (3), se excluyó del análisis estadístico una muestra de orina que no cumplía con las condiciones de toma de muestra. A la materia fecal se realizó análisis físico y microscópico como lo describe la literatura (4).

Análisis y entrega de resultados. Los resultados se organizaron estadísticamente a través de proporciones utilizando el programa SPSS 17,0. Los reportes de los resultados se entregaron personalmente a las autoridades de los cabildos indígenas participantes en presencia de la comunidad, así mismo se envió copia al Hospital Comunal de las Malvinas y a la Secretaria de Salud Municipal. Así mismo, se realizó una charla de hábitos de vida saludable e hizo entrega de una cartilla didáctica titulada: "Cuerpo sano: familias felices", diseñada por las investigadoras.

\section{Resultados}

En cuanto a la distribución de participantes, la comunidad Huitoto Muido Yasikú fue la que aporto más participantes al estudio con un total de 13 individuos que representan un 62\%, figura 1 .

En los resultados del parcial de orina, se observó la presencia de bacterias nitritos positivos y leucocitosis en un $4.8 \%$, en los tres cabildos participan- 
tes. El parasitismo intestinal en los niños fue del $86.67 \%$ para las muestras procesadas en los tres cabildos indígenas participantes en el estudio. El $53 \%$ de las muestras presentaron multiparasitismo.

Se observó que el parasito de mayor presencia es el Blastocystis hominis seguido de Endolimax nana, Entamoeba coli y Complejo E. histolytica- E. dispar en la misma proporción que Giardia lamblia. Es importante destacar que se encontró un helminto patógeno en uno de los niños de la comunidad Embera.

\section{Discusión}

El parasitismo intestinal suele presentarse de forma asintomática por lo que es necesario realizar exámenes coproparasitológicos periódicos en la población infantil de las comunidades indígenas, afirmación sustentada por los autores del estudio denominado: "Prevalencia de enteroparasitos en niños de la etnia Yukpa de Toromo estado Sulia, Venezuela" (5); ya que debido a las condiciones sociodemográficas en las que se encuentran estos individuos tienen mayor probabilidad de presentar este problema de salud pública

Se encontró semejanzas en la presencia de parásitos intestinales como Blastocystis hominis, Endolimax nana, complejo Entamoeba histolyticaldispar y Giardia intestinalis, con los hallazgos del estudio denominado: "Estado actual de las parasitosis intestinales en cuatro comunidades indigenas de Colombia" (6), detectándose en este caso la presencia de parasitismo intestinal de $79 \%$ en los cuatro cabildos participantes.

En el mismo estudio se resalta que Blastocystis hominis es el principal protozoario encontrado en la comunidad infantil, hecho que en el presente estudio se puede confirmar pues el $52.6 \%$ del total de la población reporta este parasito; a pesar que la que la patogenicidad de este microrganismo esta en discusión, si se encuentra en concentraciones mayores a 5 por campo microscópico en objetivo de $40 \mathrm{X}$ son capaces de producir alteraciones gastrointestinales.
En comparación con el estudio realizado en adultos de las mismas comunidades indígenas (7) el grupo de investigación resalta la presencia de Helmintos como Trichuris trichiuria en la población infantil, parasito geohelminto cuyo estadio infectante permanece activo durante largos periodos en la tierra, esta situación favorece que los niños se puedan contaminar fácilmente con los huevos ya que este es su sitio preferido para los juegos propios de su edad.

En el estudio se encontró la condición de poliparasitismo en varios de los niños participantes, situación preocupante porque puede llegar a ser un problema de salud pública y afectar a los demás individuos de la comunidad debido a las deficiencias sanitarias que ellos presentan.

Con respecto a la infección urinaria pese a que el $4.8 \%$ de la población se encontraba afectada es importante dar seguimiento a estos niños, pues una infección urinaria mal tratada puede ocasionar daños graves en las vías urinarias.

\section{Conclusiones}

1. Los niños de las comunidades indígenas colombianas Huitoto y Embera, residentes en Florencia, Caquetá presentan alto nivel de parasitismo intestinal.

2. Los hallazgos encontrados en los niños de estas comunidades indígenas son evidencia de la falta de hábitos de higiene y de condiciones sanitarias óptimas.

3. Se considera importante implementar brigadas periódicas de salud que permitan disminuir los casos de parasitismo intestinal e infecciones en estas comunidades vulnerables.

4. El aporte a la proyección social, constituye un avance a los conocimientos científicos, contribuyendo al mejoramiento de la calidad de vida de comunidades vulnerables y a la difusión de buenas prácticas en salud, especialmente enfocadas a la población infantil. 


\section{Referencias}

1. Organización Mundial de la Salud. La salud de los pueblos indígenas. Ginebra: OMS; 2007.

2. Campuzano G, Arbeláez M. El uroanálisis: un gran aliado del médico. Revista urología colombiana, [En línea], 2007 [Revisado 08 de Junio de 2012]; 15 (1): 6792. Disponible en:http://redalyc.uaemex.mx/redalyc/ pdf/1491/149120468005.pdf.

3. Trujillo C. Infección De Vías Urinarias. Urología Colombiana.[En línea] 2011. [Revisado 25 de Febrero de 2012]. Disponible en: http://www.consultaurologica.com/index. php?id=67

4. María de la T. Coproanálisis. El blog de MEBO Research. [En línea] 2010 [Revisado 12 de abril de 2012]. Disponible En http://olorcorporalyhalitosis.blogspot.com/2009/07/coproanalisis-analisis-de-las-heces.html.
5. Díaz A Iris, Rivero R Zulbey, Bracho M Ángela, Castellanos S María, Acurero Ellen, Calchi L Marinella et al. Prevalencia de enteroparásitos en nińos de la etnia Yukpa de Toromo, Estado Zulia, Venezuela. Rev. méd. Chile [revista en la Internet]. 2006 Ene [citado 2012 Oct 21]; 134(1): 72-78. Disponible en: http://www.scielo.cl/scielo.php?script=sci_arttext\&pi $\mathrm{d}=$ S003498872006000100010\&lng=es. doi: 10.4067/S003498872006000100010

6. Puerta L, Salazar L, Velásquez L, Vélez I. Estado actual de las parasitosis intestinales en cuatro comunidades indígenas de Colombia. Colombia. Revista Biomédica [En línea], 2011; [Revisado 03 de Enero de 2012]; 31(3): 98-99. Disponible en: http://revistabiomedica.org/index.php/biomedica/article/viewFile/554/683.

7. Jiménez L, Parrales L, Suárez N. Descripción del estado de salud de indígenas Huitoto y Embera de Florencia, Caquetá a través de pruebas de laboratorio, en el primer período de 2012. Trabajo de grado (Bacteriología y laboratorio clínico). Universidad colegio mayor de Cundinamarca. Facultad de Ciencias de la salud. 